\title{
Outcome of distal femoral fractures treated with locking compression plates
}

\author{
Girisha B. A.*, Somnath Machani, Rahul Shah, Muralidhar N.
}

Department of Orthopedics, Vydehi Institute of Medical Scinces and Research Centre, Bengaluru, Karnataka, India

Received: 24 April 2017

Revised: 03 May 2017

Accepted: 10 May 2017

\author{
*Correspondence: \\ Dr. Girisha B. A., \\ E-mail: drbagirish@gmail.com
}

Copyright: (c) the author (s), publisher and licensee Medip Academy. This is an open-access article distributed under the terms of the Creative Commons Attribution Non-Commercial License, which permits unrestricted non-commercial use, distribution, and reproduction in any medium, provided the original work is properly cited.

\section{ABSTRACT}

Background: Fixation of distal femoral fractures with a lateral plate alone is associated with nonunion and/or malunion with varus collapse. Locking compression plates may reduce the tendency of varus collapse. Hence, we evaluated the union rates and functional and anatomical outcome in patients of distal femoral fractures who were treated with locking compression plates.

Methods: This prospective study was conducted at a tertiary health care center at Bangalore between July 2010 and June 2012. Patients with distal femoral fractures were treated with locking compression plates and were followed up for at least 6 months. Outcomes were evaluated using Neer's score to assess outcomes in adult distal femoral fractures.

Results: The study included 22 patients (10 males and 11 females) among whom one patient was lost to follow up within 6 months after the procedure. All the fractures were post-traumatic. Nineteen (91\%) patients had closed fractures whereas two $(9 \%)$ had open fractures. Muller's A1 type was the most common $(n=7)$ type of fracture followed by $\mathrm{C} 2$, C1, A2 (n=4 each) and B1, A3 ( $\mathrm{n}=1$ each). Median duration of follow-up was 8 months (range: 6-18 months). The mean NEER's functional score was 80 points. Overall results were excellent in 5 (24\%) out of 21 cases and were satisfactory in $15(71 \%)$ cases and only one had an unsatisfactory result.

Conclusions: Locking compression plates offer excellent-satisfactory outcome in patients with distal femoral fractures.

Keywords: Lateral compression plate, distal femoral fractures, Neer's score

\section{INTRODUCTION}

Nowadays road traffic accidents (RTA) and construction site injuries (fall from height) have increased manifold due to rapid urbanization, crippling many young lives. Older patients especially women sustain fractures due to osteoporosis. Studies have proved bimodal distribution of supra condylar fractures of femur. ${ }^{1}$ Fractures of distal femur are complex injuries producing long-term disability. These account for $6 \%$ of all femur fractures and $31 \%$ if hip fractures are excluded. ${ }^{2,3}$ Nearly $50 \%$ of distal femur intra articular fractures are open fractures. ${ }^{1}$
The mechanism of injury in most cases is axial loading with valgus or varus or with rotational forces. ${ }^{4}$ The force acting directly over the distal femur also produces fractures. The deformities are produced primarily, by the direction of the initial fracture displacement and secondarily, by the pull of the thigh muscles. Pull of the hamstrings and quadriceps lead to limb shortening and angulation at the fracture site. ${ }^{3,5}$ Open fractures occur in $5-10 \%$ of all supracondylar fractures. The most common site for the open wound is over the anterior thigh proximal to the patella. 
As medical sciences have advanced, treatment modality for fractures has been changed. The major advances in the treatment of all types of femoral fractures were first seen in 1870 when Hugh Owen Thomas devised the "Thomas Splint". ${ }^{6-8}$ The trend of open reduction and internal fixation has become evident in the recent years with good results being obtained with AO blade plate, dynamic condylar screw, intramedullary supracondylar nail and locking compression plate. ${ }^{2}$

Operative indications are displaced intra-articular fractures, irreducible fractures with severe comminution, displaced extra-articular fractures, periprosthetic fractures, marked obesity and pathological fractures. The choice of implant is governed by operative goals. The goals are restoration of length and axial alignment anatomic reduction and articular congruity, stable fixation and early functional rehabilitation.

Fixation of distal femoral fractures with a lateral plate alone is associated with nonunion and/or malunion with varus collapse. Locking compression plates may reduce the tendency of varus collapse. Hence, we evaluated the union rates and functional and anatomcal outcome using Neer's score with locking compression plates in patients with distal femoral fractures.

\section{METHODS}

This prospective study was conducted at a tertiary health care center at Bangalore between July 2010 and June 2012. The study was approved by the institutional ethics committee and a written informed consent was obtained by all participants. The study included patients with supracondylar fracture of femur who were treated with locking compression plate and followed up for a minimum of six months at our institute. Patients with open distal femoral fractures type IIIB and C, pathological fractures other than osteoporotic, neurovascular compromise, associated tibial plateau fractures, nonunion or delayed union as well as patients who were lost to follow-up within 6 months after the procedure and children were excluded from the study.

All participants were evaluated for age, sex, mode of trauma and time interval between injury and arrival in the casualty was a part of the standard protocol. All participants underwent general physical examination, systemic examination and local examination of the fractured limb. A thorough assessment of patient to rule out injuries at other sites including head, chest, abdomen, spine or pelvis was performed. Patients were treated with intravenous fluids, oxygen and blood transfusion as appropriate required and the injured limb was immobilized in a Thomas splint with cotton pads below the distal thigh during transport of patient to the Department of Radiodiagnosis. Radiological assessment was done using anteroposterior and true lateral views of injured limb including complete knee joint, pelvis and involved femur. In case of open injuries, thorough irrigation and lavage of associated compound injuries with at least 9 litres of normal saline followed by dry or burn mesh dressings was done. Compound fractures were considered in the study. Injection ATS 1500 IU, Injection AGGS 20,000 IV, broad spectrum injectable antibiotics and analgesics were administered for compound injuries of other parts as appropriate.

Complete hemogram, renal function tests, liver function tests, coagulation profile, chest X-ray postero-anterior view, electrocardiography, 2D-Echo and other investigations were performed as required during the anaesthetic evaluation.

The limb to be operated was shaved and prepared a day before scheduled surgery. One and a half gram of second generation intravenous cephalosporin with sulbactum was administered at least 10 minutes before surgery.
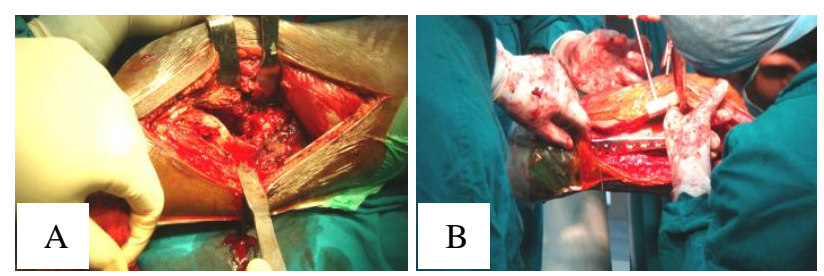

Figure 1: Fracture exposed through lateral incision (1A) and plate fixed to femur (1B).

The method used for fracture fixation was closed or minimally open reduction and internal fixation with locking compression plate. The plate and screws used were manufactured from $316 \mathrm{~L}$ stainless alloy with gundrilling technique. The anatomically precontoured locking compression plates are available from 4 holed to 14 holed with $4.5 \mathrm{~mm}$ thickness plate for lower end of femur. LCP combi-holes in the plate shaft gave an intraoperative choice between angular stability and/or compression. $^{3,7}$ Under appropriate anaesthesia, we used the standard lateral approach to distal femur (Figure 1A), with patient in supine position and a sand bag was kept below the operating knee and one below the ipsilateral hip. Skin and subcutaneous tissue were incised; superior geniculate artery was identified and ligated. Care was taken not to incise the lateral meniscus at the lateral joint margin. The vastus lateralis muscle was carefully elevated from intermuscular septum and retracted anteriorly and medially., ${ }^{3,7}$ Osteotomy of tibial tubercle and lifting along with patellar tendon improved anterior exposure to the condyles of femur. Reduction of fracture fragments was performed and temporarily secured with pointed reduction forceps and/or $\mathrm{K}$ wires. If a posterior Hoffa fragment was present, it was reduced and provisionally stabilized with $\mathrm{K}$ wire inserted from anterior to posterior. ${ }^{3,7}$

Condyles were secured with $6.5 \mathrm{~mm}$ cancellous screws. A condylar plate guide or plate itself was held laterally on the condyle to select an area, where screws would not interfere with plate placement. A $\mathrm{K}$ wire was placed 
across the femoral condyle, at the level of the knee, to indicate the joint axis and a second $\mathrm{K}$ wire placed across the patello-femoral joint on the trochlear surface. Using anatomic landmarks and $\mathrm{C}$-arm imaging, plate was mounted on the intact / reconstructed condyle without attempting to reduce the proximal portion of the fracture (Figure 1B). Length was measured using measuring device. Screws were inserted starting from central hole in the condylar portion under image control. Once reduction was satisfactory, the plate was loaded in tension using articulated tension device. The plate shaft was fixed with appropriate cortical screws after confirming final reduction of the fractures. ${ }^{3,7}$

Postoperative rehabilitation was provided to all patients which is essential to ensure the attainment and maintenance of satisfactory range of motion, strength and function of the knee joint. Rehabilitation was custom made to the patient and the fracture type to make it easier, more comfortable and more assured with firm internal fixation which will facilitate the achievement of the most useful range of motion in the first few weeks of postoperative period. Physiotherapy included with concomitant isometric quadriceps exercises and knee mobilization exercises and periodic monitoring of knee flexion was performed Periodic monitoring of knee flexion at end of $1^{\text {st }}, 2^{\text {nd }}, 3^{\text {rd }}$ week and after completion of therapy. Postoperative immobilization with knee brace was advised for severely comminuted fractures, for three weeks, although gentle physiotherapy exercises were started earlier.

Table 1: Overall rating using Neer's score.

\begin{tabular}{|lll|}
\hline Excellent & Above 85 units & $\mathbf{5}$ \\
\hline Satisfactory & $70-85$ units & 15 \\
\hline Unsatisfactory & 55-69 units & 1 \\
\hline Failure & Below 55 units & \\
\hline
\end{tabular}

Table 2: Demographic and clinical characteristics of the study population.

\begin{tabular}{|ll|}
\hline Characteristic & Observed value \\
\hline Age (years) & $31.2 \pm 8.9$ \\
\hline Male: Female & $10: 11$ \\
\hline Type of injury (n) & \\
\hline Closed & 19 \\
\hline Open & 2 \\
\hline $\begin{array}{l}\text { Muller's type of distal femoral } \\
\text { fracture (n) }\end{array}$ \\
\hline C2 \\
\hline C1 \\
\hline B1 \\
\hline A1 \\
\hline A2 \\
\hline A3 \\
\hline
\end{tabular}

Neer's functional scoring for adult distal femoral fractures was used to assess the outcome of surgery
(Table 1). ${ }^{6,9}$ It consists of 70 functional units and 30 anatomic units. The scoring includes pain, function, motion, work, gross Anatomy and Roentgenograms. ${ }^{6,9}$

The data was analysed using SPSS Version 19.0; IBM, SPSS Inc., Chicago, IL, USA. Continuous variables are expressed as mean \pm SD and categorical variables are expressed as number and percentages. Chi square test was used to compare categorical variables. A p value less than 0.05 was considered statistically significant.

\section{RESULTS}

Demographic and clinical characteristics of the study population are summarized in Table 2. The study included 22 patients among whom one male patient was lost to follow up within 6 months after the procedure; hence, not included in the outcome analysis. All the fractures in this series were post-traumatic. Road traffic accident was the most common mode of injury (47\%). None of the patients had bilateral femoral condylar fractures. Most of the patients, reported within 1st week of injury to the hospital. A total of four patients (19\%) with associated fractures including one patient with associated facial injuries, two patients had ipsilateral metatarsal and phalangeal bone fractures and one patient had ipsilateral humeral shaft fracture. Seventeen patients were operated within a week after injury whereas in the rest surgery was delayed due to initial hospitalization at other health care centers $(n=2)$ or comorbid conditions $(\mathrm{n}=2)$.

Median duration of follow-up was 8 months (range: 6-18 months). Early complications were encountered in three patients which included superficial wound infection, wound gaping and pin site infection in one patient each. Late complications observed were malunion with varus $(n=2)$, plate breakage $(n=1)$ and knee stiffness $(n=1)$. The average stay in hospital was about 14 days.

When analysed for pain, $2(9 \%)$ patients had no pain, 13 $(61 \%)$ patients had intermittent pain due to knee stiffness, $6(28 \%)$ patients had pain with fatigue. When analysed for function, 2 out of $21(9 \%)$ patients were able to return to their function as before injury. Mild restriction was noted in $14(66 \%)$ patients, whereas restriction with stair climbing was noted in $5(23 \%)$ patients.

The average range of knee flexion achieved was about $91^{\circ}$ (range: $70^{\circ}-110^{\circ}$ ). Eight $(36 \%)$ patients gained knee flexion of $100^{\circ}$ or more, $12(61 \%)$ patients gained up to $80^{\circ}$ and the remaining one patient regained a knee flexion of $70^{\circ}$.

Five $(23 \%)$ patients were able to work as before injury, $14(66 \%)$ patients had mild handicap and two $2(9 \%)$ patients shifted to alter work. When gross anatomy was analysed, two (9\%) patients developed mild varus angulation of $10^{\circ}$ and another $6(28 \%)$ patients had $5 \mathrm{~mm}$ 
shortening, and the remaining $13(61 \%)$ patients had thickening only.

Out of 21,16 patients $(76 \%)$ had near normal radiographs, two $(9 \%)$ had $10^{\circ}$ angulation and another three $(14 \%)$ patients had $5 \mathrm{~mm}$ displacement.

The mean NEER's functional score was 80 points. Overall results were excellent in $5(24 \%)$ out of 21 cases and were satisfactory in $15(71 \%)$ cases and one had an unsatisfactory result (Table 3).

Table 3: Association of Muller's fracture type with outcome.

\begin{tabular}{|llll|}
\hline Outcome & Excellent & Satisfactory & Unsatisfactory \\
\hline Type A & 5 & 7 & 0 \\
\hline Type B & 0 & 1 & 0 \\
\hline Type C & 0 & 7 & 1 \\
\hline
\end{tabular}

Excellent outcome results were observed only in type A fractures $(n=5)$ and satisfactory results were observed in the remaining type A factures. The only patient's type B fracture had satisfactory result whereas all of those with type $\mathrm{C}$ fractures had satisfactory results except one (Table 3). Although excellent outcome was observed only in patients with type A fracture, outcome was not significantly different among patients with different types of fractures $(\mathrm{p}=0.19)$.

\section{DISCUSSION}

The study reports excellent-satisfactory outcome in $95 \%$ of patients. The good outcome seen in our study can be attributed to more of type A fractures and less number of open fractures, which usually show favorable results and. Most of the series listed in Table 4 have equal or higher number of type $\mathrm{C}$ fractures and much higher cases of open fractures.

We had two cases of varus collapse; one was due to early weight bearing in one case and other case is due to gross comminution. One case had an implant failure (plate breakage) due to early weight bearing. Cases requiring hardware revision were comparable to other studies at $13 \%$ (Table 4).

Table 4: Comparison of our study findings with previously published studies.

\begin{tabular}{|c|c|c|c|c|c|c|c|c|c|}
\hline $\begin{array}{l}\frac{y}{3} \\
\frac{3}{8} \\
\frac{8}{0} \\
\frac{8}{0}\end{array}$ & 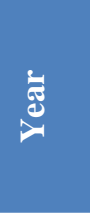 & 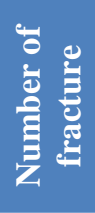 & 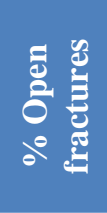 & 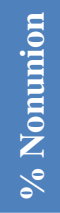 & 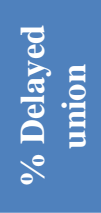 & 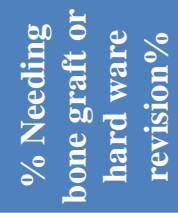 & 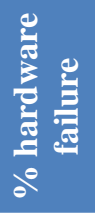 & 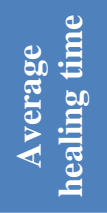 & 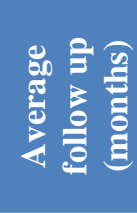 \\
\hline Schandelmaier et al $^{10}$ & 2001 & 54 & 19 & 2 & 6 & 11 & 9 & 13 & 6 \\
\hline Fankhauser et al $^{11}$ & 2004 & 30 & 47 & 0 & 3 & 20 & 20 & 12 & 20 \\
\hline Kregor et al ${ }^{12}$ & 2004 & 103 & 34 & 2 & & 10 & 5 & & 14 \\
\hline 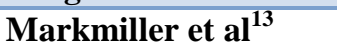 & 2004 & 20 & & 10 & 0 & 10 & 0 & 14 & 12 \\
\hline Weight et al ${ }^{14}$ & 2004 & 22 & 27 & 0 & 0 & 0 & 0 & 13 & 10 \\
\hline Schutz et al ${ }^{15}$ & 2005 & 52 & 32 & 4 & 12 & 19 & 6 & & 12 \\
\hline${\text { Vallier et } \text { al }^{16}}^{16}$ & 2006 & 46 & 54 & 9 & 15 & 20 & 13 & & 12 \\
\hline Kayali et al $^{17}$ & 2007 & 27 & 26 & 0 & & 4 & 7 & 15 & 26 \\
\hline Gaines et al $^{18}$ & 2008 & 109 & 41 & 8 & & & & & 6 \\
\hline Henderson et al ${ }^{19}$ & 2011 & 70 & 26 & 20 & & 13 & 8 & 12 & 20 \\
\hline Our study & 2012 & 21 & 9 & 0 & 0 & 13 & 5 & 16 & 8 \\
\hline
\end{tabular}

Fixation of distal femoral fractures with a lateral plate alone has historically been associated with nonunion and/or malunion with varus collapse. Prior to advent of locking plates, these problems were addressed with dual plating methods. ${ }^{20}$ Though this prevented varus collapse, extensive soft tissue stripping and medial incision increased the chance of extensor lag.

With the introduction of plates with option of locked screws, the results are encouraging, as it increases the rigidity of fixation in osteoporotic bone and in presence of periarticular or juxtaarticular comminution. ${ }^{4}$ The locking compression condylar plates provide multiple points of fixed plate to screws contact, generating greater stability and thereby reducing the tendency of varus collapse. ${ }^{8}$ Less intensive stabilization system (LISS) plating allows minimally invasive approach by submuscular insertion of plates and thereby preservation of vascularity to the lateral cortex.

In our study, radiological union was seen at an average of 16 weeks which is comparable to a study of locking compression plate by Kayali et al (average of 15 weeks). ${ }^{17}$ Overall results were excellent in 5 out of 21 cases and were satisfactory in remaining cases except one. The overall average knee score in our study was 80 , which was higher than that seen in by Schandelmaier et al $(67.7)^{21}$

The problems in fixing distal femoral fractures with osteoporosis, extensive comminution and revision surgeries following failed implant can be addressed 
effectively using locking condylar plate. ${ }^{8,22}$ We believe that locking plates represent a valuable advancement in fracture treatment. However, the limitations of this new technology and indications for its use have not been completely elucidated and the long-term results are awaited.

However, the locking plates can fail when physiological loads are outside plate design parameters. ${ }^{23}$ The locked screws can dis-engage from the plate secondary to failure of the screw to seat into the plate properly, as a result of cross-threading or when insufficient screw torque is used to engage the screw threads into the plate threads. ${ }^{23}$

To conclude, locking compression plates offer excellentsatisfactory outcome in patients with distal femoral fractures. We suggest it as treatment of choice in the management of comminuted distal femoral fractures especially in type A fractures where we have found higher Neer scores.

\section{Funding: No funding sources}

Conflict of interest: None declared

Ethical approval: The study was approved by the institutional ethics committee

\section{REFERENCES}

1. Martinet O, Cordey J, Harder Y, Maier A, Buhler M, Barraud GE. Epidemiology of fracture of distal femur. Injury. 2000;31:62-3.

2. Reudi TP, Buckley RE, Moran CG. A O principles of fracture managament. 2nd edition. Switzerland: A O Publishing; 2007.

3. Collne AC, Wiss DA. Rockwood and Green fracture in adults. 7th edition. Philadelphia: LWW; 2009.

4. Egol KA, Kubiak EN, Fulkerson E, Kummer FJ, Koval KJ. Biomechanics of Locked Plates and Screws. J Orthop Trauma. 2004;18(8):488-93.

5. Rockwood CA, Green DP. Fractures in adult. 4th edition, Philadelphia: LWW; 1996.

6. Neer CS II, Grantham SA, Shelton ML. Supracondylar fracture of the adult femur- a study of one hundered and ten cases. JBJS Am. 1967;49(4):591-613.

7. Whittel AP, Wood GW, Canale T. Cambells Operative Orthopaedics. 11th edition: Elsevier Inc; 2008.

8. Kubiak EN, Fulkerson E, Strauss E, Egol KA. The evolution of locked plates. J Bone J Surg. 2006;88(4):189-200.

9. Henderson CE, Kuhl LL, Fitzpatrick DC. Healing complications are common after locked plating for distal femur fractures. Clin orthop Relat Res. 2011;469:1757-65.

10. Schandelmaier P, Partenheimer A, Koenemann B, Grun OA, Krettek C. Distal femoral fractures and LISS stabilization. Injury. 2001;32(3):55-63.
11. Fankhauser F, Gruber G, Schippinger G, Boldin C, Hofer HP, Grechenig W, et al. Minimal-invasive treatment of distal femoral fractures with the LISS (Less Invasive Stabilization System): a prospective study of 30 fractures with a follow up of 20 months. Acta Orthop Scand. 2004;75(1):56-60.

12. Kregor PJ, Stannard J, Zlowodzki M, Cole PA, Alonso J. Distal femoral fracture fixation utilizing the Less Invasive Stabilization System (L.I.S.S.): The technique and early results. Injury. 2001;32(3):32-47.

13. Markmiller M, Konrad G, Sudkamp N. Femur-LISS and distal femur nail for fixation of distal femoral fractures. Clin Orthop and Relat Res. 2004;426:2527.

14. Weight M, Collinge C. Early results of the less invasive stabilization system for mechanically unstable fractures of the distal femur. J Orthop Trauma 2004;18:503-8.

15. Schutz M, Muller M, Krettek C, Hontzsch D, Regazzoni P, Ganz R, et al. Minimally invasive fracture stabilization of distal femoral fractures with the LISS: a prospective multicenter study. Results of a clinical study with special emphasis on difficult cases. Injury. 2001;32(3):48-54.

16. Vallier HA, Hennessey TA, Sontich JK, Patterson BM. Failure of LCP condylar plate fixation in the distal part of the femur-A report of six cases. J Bone J Surg Am. 2006;88(4):846- 53.

17. Kayali C, Agus H, Turgut A. Successful results of minimally invasive surgery for comminuted supracondylar femoral fractures with LISS: comparative study of multiply injured and isolated femoral fractures. J Orthop Sci. 2007;12:458-65.

18. Gaines RJ, Sanders R, Sagi HC, Haidukewych GJ. Titanium versus stainless steel locked plates for distal femur fractures: is there any difference? OTA abstract. 2008;55:8.

19. Henderson CE, Lujan T, Bottlang M, Fitzpatrick DC, Steve MM, Marsh JL. Stabilization of distal femur fractures with intramedullary nails and locking plates: differences in callus formation. Iowa Orthop J. 2010;30:61-8.

20. Sanders R, Swiontowski M, Rosen H, Helfet D. Double-plating of comminuted, unstable fractures of the distal part of the femur. J Bone J Surg Am. 1991;73(3):341-6.

21. Schandelmaier P, Partenheimer A, Koenemann B, Grun OA, Krettek C. Distal femoral fractures and LISS stabilization. Injury 2001;32(3):55-63.

22. Giannoudis PV, Schneider E. Principles of fixation of osteoporotic fractures. J Bone J Surg $\mathrm{Br}$. 2006;88(10):1272-8.

23. Sommer C, Babst R, Muller M, Hanson B. Locking Compression Plate Loosening and Plate Breakage A Report of Four Cases. J Orthop Trauma. 2004;18(8):571-7.

Cite this article as: Girisha BA, Machani S, Shah R, Muralidhar N. Outcome of distal femoral fractures treated with locking compression plates. Int J Res Orthop 2017;3:676-80. 